\title{
Writing and Reviewing Scientific Papers: A Priority for Teaching Professionals
}

\author{
Wizra Saeed ${ }^{1}$
}

Received: 26 December 2021; Accepted:

27 December 2021

Senior Assistant Professor, Department of Professional Psychology, Bahria University, Islamabad Campus, Pakistan.

\section{Corresponding Author Email:}

wizrasaeed@gmail.com

"It's never been a better time to be a writer-or aspire to become one".

Writing is a skill mastered over time with careful study and practice. Thankfully, some of the world's finest writers, those who perfected the trade and whose names have been passed down through the generations, have left us not just with their stories but also with their names. Between producing their novels, short tales, and poems, many of them spent time formalizing their writing theories, tactics, and habits (Leibowitz, 2017).

Critical and creative writing skills are the ability of a thinker, select words and sentences correctly in organizing the voice of our inner thoughts on the canvas of others' minds that are too often overlooked these days. Success in the workplace depends on good writing skills. In addition to email correspondence, project reports, sales proposals, or scientific research that allow you to showcase your skills and quality work, it will also serve as an inspiration and guide for aspiring professionals. The good piece of writing can make your writing noticed by larger audience. The art of skilled writing gives oneself happiness, and a sense of contentment and growth (Cotos, 2014).

Every field involves writing, so academia also has the significance of writing. Some authors recorded their thoughts on writing in books, essays, and letters to their friends, research papers, and editorials. Generally, the benefits of scholarly and academic writing are not cared for these days, thus, we do not go for scientific writing. Getting the most out of these benefits begins with accepting the simple truth that we are already writers (Marshbank, 2018). One has to use thinking skills to generate thoughts to develop a piece of information so that one's thinking could transform into an impressive writing. But as a teacher, one should write creatively so that readers get an inspiration and their creative faculties may open up. All teachers are writers to some extent and have responsibility to evoke readers creativity.

Writing reflectively can be a simple but powerful tool for improving our professional and personal lives as a teacher. Having documented our days enables us to analyze successes and improve after failures. Writing creatively opens up and help us grow our cognitive abilities (Cotos, 2014). Writing can make us better thinkers too. One way to write creatively is to write spontaneously and on regular basis to develop a habit. In such a way, writing improves our teaching skills too. As good writers and teachers, we can contribute to build writing skills in our students too.

Write-not necessarily well. That's the goal. Everyone has hard time writing; few do it well. It's true, however, that writing is a joy: the profound feeling of effort when we write or type isn't unique to teachers. It is experienced by the students, too. In addition, having genuine discussions with learners about writing difficulties fosters a more collaborative literary classroom atmosphere (Marshbank, 2018).

In this regard, another important aspect is to read and review the scientific works of other researchers since it is not possible for a writer to come forward with new ideas and competitive pieces of work unless they

This article is distributed under the terms of the Creative Commons Attribution Non Commercial 4.0 License (http://www.creativecommons.org/licenses/by-nc/4.0/) which permits non-Commercial use, reproduction and distribution of the work without further permission provided the original work is attributed as specified. 
choose to be an avid reader. Nevertheless, reviewing the scientific papers enhances critical analytical skills, and the writer is embellished with innovative knowledge in depth.

As a reviewer of scientific work, the writer would be seen as iconic in the field of research because he would have gotten through a wide variety of academia, and his knowledge is comparable to others in the area.

Reading provides a pathway to awareness and meaningful learning. In terms of scientific work, reading must be summed up with the reviewing element so that the professionals would have an elaborate and clear path towards enhancing their capabilities of writing and learning.

The value acquired from reading is largely determined by how events are analyzed. Reviewing gives you the chance to add value and significance to your experiences, no matter how "little" or "big," "negative" or "good." Individuals and organizations might become trapped at a certain stage of development if they do not evaluate. Reviewing offers a variety of ways for going through this stage and restarting the learning and development cycles. Reviewing can aid in clarifying, achieving, measuring, and glorifying goals. People may have a habit of looking back on events from their 'regular' perspective. People can escape normal vision and learn from the wider picture by seeing an experience from the viewpoint of others and viewing' an adventure through a range of 'windows' (reviewing procedures). By reviewing activities, we demonstrate that we care about what people are going through, appreciate what they have to say, and are concerned about how each person's learning and development is progressing. People will learn better if they feel cared for, cherished, and respected as individuals (Greenaway, n.d.).

It is not always simple to speak openly about one's life experiences. People can find the medium, setting, symbol, or subject through which they can most easily express themselves by using an inventive and sensitive evaluation approach. The expressive and creative arts might be especially beneficial in this situation (Greenaway, n.d.).

Simply summing up, we can say that writing and reviewing are the two fundamental aspects of advancing scientific knowledge and academic development. So, if a professional is eager to maintain high performance and a well-qualified profile, he must have the grip on scientific writing and review and read the past, current, and ongoing studies. Education provides educators with many opportunities to share their ideas and writing and reviewing is a cost-effective way to do so.

\section{References}

Cotos, E. (2014). Learning and teaching challenges of research writing. Genre-Based Automated Writing Evaluation for L2 Research Writing, 9-39. https://doi.org/10.1057/978113733 3377_2

Greenaway, R. Reviewing skills training. https://reviewing.co.uk/_review.ht $\mathrm{m}$

Leibowitz, G. (2017). 50 inspiring quotes about writing from the world's greatest authors. Inc.com. https://www.inc.com/glennleibowitz/50-quotes-from-famousauthors-that-will-inspire-yo.html

Marshbank, A. (2018). How Teachers Benefit From Writing. https://www.edutopia.org/article/ho w-teachers-benefit-writing 